\title{
Combination effect of fluoride dentifrices and varnish on deciduous enamel demineralization
}

\begin{abstract}
Alessandra Gatti(a)
Lucila Basto Camargo(b)

José Carlos Pettorossi Imparato(b)

Fausto Medeiros Mendes ${ }^{(b)}$

Daniela Prócida Raggio(b)
\end{abstract}

(a) Departamento de Odontopediatria,

Faculdade de Odontologia, São Leopoldo

Mandic, Campinas, SP, Brazil.

(b) Departamento de Ortodontia e Odontopediatria, Faculdade de Odontologia, Universidade de São Paulo, São Paulo, SP, Brazil.

Declaration of Interests: The authors certify that they have no commercial or associative interest that represents a conflict of interest in connection with the manuscript.

Corresponding author:

Daniela Prócida Raggio

E-mail: danielar@usp.br

Received for publication on Mar 24, 2011 Accepted for publication on Sep 05, 2011

\begin{abstract}
The aim of this study was to evaluate the anticaries potential of 500 or 1100 ppm F dentifrices combined with fluoride varnish using a $\mathrm{pH}$-cycling regimen. Seventy primary canines were covered with nail polish, leaving a $4 \times 4 \mathrm{~mm}$ window on their buccal surface, and randomly assigned into 7 groups $(\mathrm{n}=10)$ : S: sound enamel not submitted to the $\mathrm{pH}$-cycling regimen or treatment; $\mathrm{N}$ : negative control, submitted to the $\mathrm{pH}$-cycling regimen without any treatment; D1 and D2: subjected to the $\mathrm{pH}$-cycling regimen and treated twice daily with 1100 or 500 ppm F dentifrice, respectively; VF: fluoride varnish (subjected to F-varnish before and in the middle of the $\mathrm{pH}$-cycling regimen); and VF+D1 and VF+D2. After 10 days, the teeth were sectioned, and enamel demineralization was assessed by cross-sectional hardness at different distances from the dental surface. Data were analyzed using a two-way ANOVA followed by Tukey's test. Dentifrice with 1100 ppm F and the combination of F-varnish with the dentifrices significantly reduced enamel demineralization compared with the negative control $(\mathrm{p}<0.05)$, but the isolated effects of F-varnish and dentifrice with low concentration were not significant $(p>0.05)$. The effect of combining F-varnish with the dentifrices was not greater than the effect of the dentifrices alone $(\mathrm{p}<0.05)$. The data suggest that the combination of F-varnish with dentifrices containing 500 and $1100 \mathrm{ppm} \mathrm{F}$ is not more effective in reducing demineralization in primary teeth than the isolated effect of dentifrice containing $1100 \mathrm{ppm} F$.
\end{abstract}

Descriptors: Demineralization; Dental Enamel; Dentifrices; Tooth, Deciduous.

\section{Introduction}

Topical fluoride treatments have frequently been used to prevent dental caries for over three decades. ${ }^{1,2}$ The decline in the prevalence of caries is greatly due to fluoridated water supplies and professional topical application but is primarily due to the widespread use of fluoride toothpaste. ${ }^{3}$

The regular use of fluoridated dentifrice may be a beneficial preventative measure, independent of the occurrence of caries ${ }^{3}$. However, Ögaard et al. ${ }^{4}$ recommended that when the risk of caries is high, this measure should be conducted with high concentration methods. The benefit of combining fluoridated dentifrice with professional applications has not been clearly established, and more studies are necessary. ${ }^{5}$

Considering the relationship between the prevalence of dental fluo- 
rosis and the use of fluoride dentifrice, and because young children have not fully developed their swallow reflex and may therefore ingest large amounts of dentifrice during tooth brushing, ${ }^{6}$ several preventative measures have been suggested. ${ }^{7}$ Some recommendations have been made for tooth brushing in children younger than six years old:

- non-fluoridated dentifrice,

- a small amount of dentifrice ${ }^{8}$ and

- dentifrice with reduced fluoride concentrations. ${ }^{9}$

Therefore, it is necessary to assess if dentifrices with lower fluoride concentrations (500 ppm F) that are targeted to children younger than six years old are effective against demineralization, and if this preventive effect is the same as those for $1100 \mathrm{ppm} \mathrm{F}$ dentifrices.

The present study aimed to assess the preventive effect of $500 \mathrm{ppm} \mathrm{F}$ and $1100 \mathrm{ppm}$ F fluoridated children's dentifrices and fluoride varnish in vitro, either applied in combination or alone, on primary teeth enamel after a caries challenge.

\section{Methodology}

This research was approved by an Ethical Board. Seventy primary canines from the Human Tooth Bank were used. The samples were assessed by visual inspection and were free of dental caries or enamel defects.

The root portion of all teeth was sealed with epoxy resin (Araldite ${ }^{\circledR}$, Brascola, Florianópolis, Brazil) and then covered with red nail polish (Colorama, São Paulo, Brazil). A $4 \times 4 \mathrm{~mm}$ window area on the buccal surface was left free of nail varnish. All teeth were previously cleaned with a detergent solution (Tergencal ${ }^{\circledR}$, Biodinâmica, Curitiba, Brazil) and pumice powder using a low speed motor. The teeth were then left under running water for one minute to eliminate debris.

Teeth were submitted to the formation of artificial caries by $\mathrm{pH}$ cycling, ${ }^{10}$ keeping the teeth in demineralizing solution $\left(\mathrm{CaCl}_{2} 2.2 \mathrm{mM}, \mathrm{NaH}_{2} \mathrm{PO}_{4}\right.$ $2.2 \mathrm{mM}$ and acetic acid $0.05 \mathrm{M}$; $\mathrm{pH}$ of 4.5 , adjusted with $\mathrm{KOH} 1 \mathrm{M} ; ;^{13} 15 \mathrm{~mL}$ per tooth) for 3 hours and in remineralizing solution $\left(\mathrm{CaCl}_{2} 1.5 \mathrm{mM}, \mathrm{NaHPO}_{4}\right.$ $0.9 \mathrm{mM}$ and $\mathrm{KCl} 0.15 \mathrm{mM}$; $\mathrm{pH}$ of $7.0 ; 15 \mathrm{~mL}$ per tooth) for 21 hours. A total of 10 cycles were conducted. The teeth were briefly washed in deionized water between solutions and placed in artificial saliva for 30 minutes $\left(\mathrm{CaCl}_{2}[15 \mathrm{mg}], \mathrm{MgCl}_{2}[5 \mathrm{mg}]\right.$, $\mathrm{KCl}$ [0.1 g], KSCN [10 mg], $\mathrm{Na}_{2} \mathrm{HPO}_{4}$ [40 mg], sodium carboxymethylcellulose $[1.0 \mathrm{~g}]$, methylparaben $[0.1 \mathrm{~g}]$ and water $[1 \mathrm{~L}] ; \mathrm{pH}$ of 7.0$)$. The deremineralizing solutions were changed daily, and the artificial saliva was changed at every treatment.

One of the groups was comprised of sound enamel (S), was not submitted to $\mathrm{pH}$ cycling and had no treatment. Group $S$ was kept in deionized water for a later hardness assessment.

The negative control (N) group had no treatment but was submitted to $\mathrm{pH}$ cycling. The remaining five groups (VF, VF+D1, VF+D2, D1, D2) received topical fluoride treatment. Groups VF, VF+D1 and $\mathrm{VF}+\mathrm{D} 2$ were treated with the fluoridated varnish Duraphat $^{\circledR}$ (Colgate-Palmolive, São Paulo, Brazil) (22600 ppm F NaF and $\mathrm{pH}$ of 7.0) on the $5^{\text {th }}$ and $10^{\text {th }}$ day of the $\mathrm{pH}$ cycling. Duraphat ${ }^{\circledR}$ was applied to the delimited area $(4 \times 4 \mathrm{~mm})$. The teeth were then stored in the remineralizing solution for 5 hours. The varnish was then carefully removed with acetone, and the teeth were washed with deionized water for one minute ${ }^{11}$ and again immersed in the remineralizing solution. The varnish application was conducted within the 21 hours that the teeth were kept in the remineralizing solution.

During the $\mathrm{pH}$ cycling, the $\mathrm{VF}+\mathrm{D} 1$ and $\mathrm{VF}+\mathrm{D} 2$ groups were treated with the varnish as well as fluoridated dentifrice, while the D1 and D2 groups were only treated with fluoridated dentifrice. The $\mathrm{VF}+\mathrm{D} 1$ and D1 groups were treated with the dentifrice Tandy ${ }^{\circledR}$ (Colgate-Palmolive, São Paulo, Brazil) (1100 ppm F in NaF, pH of 7.0), and the VF+D2 and D2 groups were treated with Colgate Baby Barney ${ }^{\circledR}$ (Colgate-Palmolive, São Paulo, Brazil) (500 ppm F in $\mathrm{NaF}, \mathrm{pH}$ of 6.9 ). The dentifrices were applied twice daily on the enamel at 10 a.m. and 4 p.m. by manually brushing the surface for 1 minute before changing solutions. After every brushing period, the teeth were briefly washed in deionized water.

To standardize the minimum amount of dentifrice used in the experiment, the lids of the Tandy ${ }^{\circledR}$ (Colgate-Palmolive, São Paulo, Brazil) and Col- 
gate Baby Barney ${ }^{\circledR}$ (Colgate-Palmolive, São Paulo, Brazil) were used. These lids close under pressure, and both have similar compartments for dentifrice dosage. According to Chedid and Cury, ${ }^{10}$ the dentifrice quantity accumulated in the lids is $0.16 \mathrm{~g}$ on average. The standardized technique is to press the brush once on the top of the lid. The penetration of the brush into the lid is limited by the depth of the lid.

The teeth were then immersed in orthophtalic resin and cut along the crown's longitudinal axis through the middle of the window area to assess the hardness. The cut surface was polished in a rotating machine (Arotec Aropol 2V, São Paulo, Brazil) using sand paper with grits of 320,600, and 1200 . The 320 grit paper was used for 30 seconds, and the remaining 2 grit papers were used for 60 seconds each under running water. The polished surface was verified by visual inspection before using the next grit paper. For this procedure, the samples were held on top of the sandpaper by hand, with minimum pressure. The final polish was conducted by felt disks and diamond paste (Diamond Excel, FGM, Florianópolis, Brazil) at low speed. The samples were later washed and placed in the ultra-sound bath for 12 minutes to remove debris.

The cross sectional hardness measurements were made using a hardness tester (Pantec-Digital Microhardness tester HVS-1000, Panambra Ind. e Téc- nica S/A, São Paulo, Brazil) with a Knoop indentor and static load of $25 \mathrm{~g}$ and with 5 seconds of dwell time. ${ }^{10}$

Three rows of 5 indentations each, separated by $100 \mu \mathrm{m}$, were made at 20,40,60, 80 and $100 \mu \mathrm{m}$ from the outer dental surface of the exposed area. The mean hardness values $\left(\mathrm{kg} / \mathrm{mm}^{2}\right)$ of the 3 rows at each distance from the surface were then averaged and statistically analyzed within and between treatments. A Kolmogorov-Smirnov test was used to verify the sample distribution, and a two-way ANOVA with repeated measures (for distance) and a post-hoc Tukey test were used to verify differences in hardness between treatments and distances from the surface. The statistical analyses were conducted with the statistical software SPSS (IBM Corp, New York, USA) version 13.0, with a $5 \%$ significance level.

\section{Results}

Results reached statistical significance for the group and distance factors and the interaction between group and distance, which indicates that the effect of the treatments was different, depending on the depth of the enamel surface.

The demineralization data according to the distance from the dental surface for the negative control $(\mathrm{N})$ group showed that the produced lesion was narrow because the statistical difference was only
Table 1 - The means and standard deviations $(n=10)$ of microhardness $\left(\mathrm{kg} / \mathrm{mm}^{2}\right)$ according to the treatments and distance from the surface.

\begin{tabular}{|c|c|c|c|c|}
\hline \multirow{2}{*}{ Group } & \multicolumn{4}{|c|}{ Distance from dental surface $(\mu \mathrm{m})$} \\
\hline & 20 & 40 & 60 & 80 \\
\hline S (Sound) & $260.4(85.4)^{\mathrm{Ca}}$ & $288.5(66.9)^{\mathrm{B}, \mathrm{C}, \mathrm{Da}}$ & $302.8(76.0)^{\mathrm{B} a}$ & $282.8(62.6)^{A, B a}$ \\
\hline$N$ (negative control) & $148.7(71.5)^{\mathrm{A} a}$ & $238.0(44.7)^{\mathrm{Ab}}$ & $252.6(43.1)^{\mathrm{Ab}}$ & $255.0(45.1)^{\mathrm{Ab}}$ \\
\hline $\begin{array}{c}\text { VF (fluoride } \\
\text { varnish treatment) }\end{array}$ & $174.9(58.9)^{\mathrm{Aa}}$ & $240.3(46.6)^{\mathrm{Ab}}$ & $254.1(60.6)^{A b}$ & $249.6(64.8)^{A b}$ \\
\hline $\begin{array}{c}\text { D1 (1 } 100 \text { ppm } \\
\text { dentifrice treatment) }\end{array}$ & $258.7(54.5)^{\mathrm{Ca}}$ & $275.9(62.9)^{\mathrm{A}, \mathrm{B}, \mathrm{C} a}$ & $284.9(56.3)^{A, B a}$ & $282.9(78.1)^{A, B a}$ \\
\hline $\begin{array}{c}\text { D2 (500 ppm } \\
\text { dentifrice treatment) }\end{array}$ & $186.4(75.7)^{A, B a}$ & $254.3(63.3)^{A, B ~ b}$ & $285.3(57.9)^{\mathrm{A}, \mathrm{B} b}$ & $284.4(56.5)^{A, B} \mathrm{~b}$ \\
\hline $\mathrm{VF}+\mathrm{D} 1$ & $249.6(65.3)^{B, C a}$ & $306.9(50.3)^{B, C, D a, b}$ & $318.3(43.2)^{\mathrm{B}, \mathrm{Cb}}$ & $303.7(43.7)^{\mathrm{B} \mathrm{b}}$ \\
\hline $\mathrm{VF}+\mathrm{D} 2$ & $243.8(42.4)^{\mathrm{B}, \mathrm{Ca}}$ & $328.3(84.9)^{\mathrm{B}, \mathrm{C}, \mathrm{D} b}$ & $361.0(73.5)^{c b}$ & $361.1(63.3)^{c b}$ \\
\hline
\end{tabular}

Distinct capital letters show differences between groups at each distance (within columns), while distinct small letters show significant differences among distances for each group (in the lines) after a two-way ANOVA and Tukey's test $(p<0.05)$. $\mathrm{S}=$ not subjected to the $\mathrm{pH}$-cycling regimen or any treatment; $\mathrm{N}=$ subjected to the $\mathrm{pH}$-cycling regimen without any treatment; $\mathrm{VF}, \mathrm{D} 1, \mathrm{D} 2, \mathrm{~V}+\mathrm{D} 1$ and $\mathrm{V}+\mathrm{D} 2$ = subjected to the $\mathrm{pH}$-cycling regimen and respective treatments. 
observed at a distance of $20 \mu \mathrm{m}$ from the enamel surface (Table 1).

When the effect of the treatments was compared with the negative control group at each distance from the surface, the treatments with F-varnish $(\mathrm{V})$ and $500 \mathrm{ppm} F$ dentifrice (D2) were not effective $(\mathrm{p}>0.05)$ in reducing enamel demineralization in all depths analyzed (Table 1). At $20 \mu \mathrm{m}$ of depth, the dentifrice with 1100 ppm F (group D1) significantly reduced demineralization compared with group $\mathrm{N}$ $(\mathrm{p}>0.05)$, but did not differ in the other distances $(\mathrm{p}>0.05)$. The groups $\mathrm{VF}+\mathrm{D} 1$ and $\mathrm{VF}+\mathrm{D} 2$ did not significantly differ at any distance from the surface $(\mathrm{p}>0.05)$. The combination of dentifrice and varnish (groups $\mathrm{VF}+\mathrm{D} 1$ and $\mathrm{VF}+\mathrm{D} 2$ ) significantly reduced demineralization compared with the $\mathrm{N}$ group at all distances evaluated $(\mathrm{p}<0.05)$, but the combination did not differ from the dentifrice groups at most distances from the surface $(\mathrm{p}>0.05)$.

\section{Discussion}

The present study used the $\mathrm{pH}$ cycling suggested by Chedid and Cury, ${ }^{10}$ which is specifically indicated for primary teeth. The daily 3 -hour demineralization cycle is related to effects that result when the patient ingests cariogenic products and does not remove the biofilm. In relation to this in vitro study, it was observed that there was a general enhanced preventative effect from combining fluoridated varnish with dentifrices $(\mathrm{VF}+\mathrm{D} 1$ and $\mathrm{VF}+\mathrm{D} 2)$ compared with other groups. The preventative effect of low-fluoride dentifrice is still a concern in the literature. Winter et al. ${ }^{12}$ and Vilhena et al. ${ }^{9}$ demonstrated good performance in preventing new caries lesions in clinical trials using $550 \mathrm{ppm} \mathrm{F}$ and 500 ppm F toothpaste, respectively. However, Lima et al. ${ }^{13}$ showed that in active caries in children, the 1100 ppm F performed better than the 500 ppm F. The low anticaries efficacy of $500 \mathrm{ppm} F$ dentifrice compared with 1000-1100 ppm F dentifrice has been shown experimentally, ${ }^{14}$ and it has also been supported by evidence. ${ }^{15}$

Our results suggest that the fluoridated varnish alone was not effective in avoiding mineral loss. The results are consistent with the in vitro study conducted by Maia et al. ${ }^{11}$ Grodzka et al. ${ }^{16}$ found that the best preventative effect may be achieved when fluoridated varnish is combined with other forms of fluoride supplements. Similarly, the present study demonstrated that lower mineral loss values were obtained in the VF+D2 and VF+D1 groups. However, other studies ${ }^{2,11}$ have suggested that the combination of low (fluoridated dentifrice) and high fluoride concentration methods (fluoridated varnish) do not have additional benefits in remineralization and fluoride incorporation.

The professional cleaning was conducted to simulate the effects of the oral environment. Although the acquired pellicle is permeable to small ions, it tends to act as a barrier to diffusion, and it reduces the possible mineral transportation between the tooth and the oral environment, thus promoting or interfering with the remineralization process. However, Hellwig et al. ${ }^{17}$ reported that applying fluoridated varnish on demineralized enamel covered by young biofilm only interfered in the formation of soluble fluoride $\left(\mathrm{CaF}_{2}\right)$. It did not impair the fluoride ionic exchange or its incorporation into the enamel ${ }^{17}$ and reduced caries lesion progression if the fluoride availability in the biofilm was high. ${ }^{14}$

Considering that only the varnish group had enamel cleaned with acetone to remove resin residue, this procedure might cause damage to the fluoride product formed. Bruun and Givskov ${ }^{18}$ tested this hypothesis and showed that acetone could not dissolve the $\mathrm{CaF}_{2}$ from the enamel treated with varnish.

A comparison of the present study with other research is difficult to conduct due to differences in experimental design, $\mathrm{pH}$-cycling models, the type of enamel used (primary, permanent or bovine), the trademark of the products used and the different concentrations of fluoride. However, based on our results, some considerations can be extrapolated.

Independent of the distance from the surface, the VF group always showed the lowest values for hardness. For the most superficial layers of the enamel, such as within $20 \mu \mathrm{m}$, where the teeth initially suffer cariogenic action, a decrease in hardness was observed for all treatments compared with the control group $(\mathrm{N})$. At this distance, the effect of the 500 ppm F dentifrice (D2) was significantly different 
from the 1100 ppm F (D1) dentifrice, which showed greater hardness. The combination of fluoride varnish with 500 ppm $\mathrm{F}(\mathrm{VF}+\mathrm{D} 2)$ and $1100 \mathrm{ppm} F$ (VF+D1) dentifrices also did not show an advantage compared with the 1100 ppm F dentifrice (D1) used alone.

Delbem et al. $(2006)^{19}$ verified the $\mathrm{pH}$ influence $(4.0,5.0,6.0$ and 7.0) and the anti-cariogenic effect of $0.02 \%, 0.05 \%$ and $0.1 \% \mathrm{NaF}$ solutions using a $\mathrm{pH}$-cycle model in bovine enamel. The results show that the $\mathrm{pH}$ influenced the percentage of surface microhardness loss (\% SMH) in the $0.02 \%$ and $0.05 \%$ $\mathrm{NaF}$ at a $\mathrm{pH}$ of 4.0. In such solutions, the mineral loss was lower when compared with a $\mathrm{pH}$ of 7.0 $(\mathrm{p}<0.05)$. The authors concluded that the acidification of solutions with low fluoride concentrations reduced mineral loss. The availability of saliva was also determined in the low-fluoride dentifrices with lower $\mathrm{pH}$ values. ${ }^{20}$

However, it should be stated that these results were obtained in an in vitro study, without diluting the dentifrice after application and biofilm forma-

\section{References}

1. Marinho VCC, Higgins JPT, Logan S, Sheiham A. Fluoride toothpastes for preventing dental caries in children and adolescents. Cochrane Database Syst Rev. In: The Cochrane Library, Issue 08, Art. No. CD002278. DOI: 10.1002/14651858. CD002278.pub1.

2. Marinho VCC, Higgins JPT, Logan S, Sheiham A. Fluoride varnishes for preventing dental caries in children and adolescents. Cochrane Database Syst Rev. In: The Cochrane Library, Issue 08, Art. No. CD002279. DOI: 10.1002/14651858. CD002279.pub3.

3. Cury JA, Tenuta LM, Ribeiro CC, Paes Leme AF. The importance of fluoride dentifrices to the current dental caries prevalence in Brazil. Braz Dent J. 2004 Mar;15(3):167-74.

4. Ögaard B, Seppa L, Rolla G. Professional topical fluoride aplications - clinical efficacy and mechanism of action. Adv Dent Res. 1994 Jul;8(2):190-201.

5. Zimmer S. Caries-preventive effects of fluoride products when used in conjunction with fluoride dentifrice. Caries Res. 2001 Jul;35(suppl 1):18-21.

6. Moraes SM, Pessan JP, Ramires I, Buzalaf MA. Fluoride intake from regular and low fluoride dentifrices by 2-3-year-old. Braz Oral Res. 2007 Jul-Sep; 21 (3): 234-240.

7. Wong MC, Clarkson J, Glenny AM, Lo EC, Marinho VC, Tsang BW, Walsh T, Worthington HV. Cochrane Reviews on tion, among other factors, and the results can therefore be different in vivo. More research, especially clinical trials, is necessary to confirm if the association of children's fluoride dentifrices and fluoride varnish can provide an adequate preventative effect in primary enamel.

Nevertheless, our data using this $\mathrm{pH}$-cycling model are consistent with two systematic reviews: one showing that there is evidence for an anticaries effect if the dentifrice concentration is higher than $1100 \mathrm{ppm} \mathrm{F},{ }^{15}$ and another concluding that the preventive effect of combining topical fluorides (dentifrice, mouth rinse or professional application) is modest compared with the isolated effect of fluoride dentifrice. ${ }^{21}$

\section{Conclusion}

The findings suggest that the combination of F-varnish with dentifrices containing 500 or $1100 \mathrm{ppm} F$ is not more effective in reducing demineralization in primary teeth than the isolated effect of dentifrice containing $1100 \mathrm{ppm}$.

the Benefits/Risks of Fluoride Toothpastes. J Dent Res. J Dent Res. 2011 May;90(5):573-9.

8. Villena RS. An investigation of the transverse technique of dentifrice application to reduce the amount of fluoride dentifrice for young children. Pediatr Dent. 2000 Jul-Aug;22(4):312-7.

9. Vilhena FV, Olympio KP, Lauris JR, Delbem AC, Buzalaf MA. Low-fluoride acidic dentifrice: a randomized clinical trial in a fluoridated area. Caries Res. 2010 Sep-Oct;44(5):478-84.

10. Chedid SJ, Cury JA. Effect of 0,02\% NaF solution on enamel demineralization and fluoride uptake by deciduous teeth in vitro. Braz Oral Res. 2004 Jan-Mar;18(1):18-22.

11. Maia LC, Souza IPR, Cury JA. Effect of a combination of fluoride dentifrice and varnish on enamel surface rehardening and fluoride uptake in vitro. Eur J Oral Sci. 2003 Feb;111:6872.

12. Winter GB, Holt RD, Willians BF. Clinical trial of low-fluoride toothpaste for young children. Int Dent J. 1989 Dec;39(4):22735.

13. Lima TJ, Ribeiro CC, Tenuta LM, Cury JA. Low-fluoride dentifrice and caries lesion control in children with different caries experience: a randomized clinical trial. Caries Res. 2008 Jan-Feb;42(1):46-50.

14. Cury JA, do Amaral RC, Tenuta LM, Del Bel Cury AA, Tabchoury CP. Low-fluoride toothpaste and deciduous enamel 
demineralization under biofilm accumulation and sucrose exposure. Eur J Oral Sci. 2010 Aug;118(4):370-5.

15. Walsh T, Worthington HV, Glenny AM, Appelbe P, Marinho VC, Shi X. Fluoride toothpastes of different concentrations for preventing dental caries in children and adolescents. Cochrane Database Syst Rev. 2010 Jan 20;(1):CD007868.

16. Grodzka, K, Augustyniak L, Budny, J, Czarnocka K, Janicha $\mathrm{J}$, Mlosek K, et al. Caries increment in primary teeth after application of Duraphat fluoride varnish. Community Dent Oral Epidemiol. 1982 Apr; 10(2):55-9.

17. Hellwig E, Klimek J, Schmidt HF, Egerer R. Fluoride uptake in plaque-covered enamel after treatment with the fluoride lacquer Duraphat. J Dent Res. 1985 Aug;64(8):1080-3.

18. Bruun C, Givskov H. Formation of $\mathrm{CaF}_{2}$ on sound enamel and in caries - like enamel lesions after different forms of fluoride applications in vitro. Caries Res. 1991 Mar-Apr;25(2):96-100.
19. Delbem ACB, Tiano GC, Alves KMRP, Cunha RF. Anticariogenic potential of acidulate solutions with low fluoride concentration. J Appl Oral Sci. 2006 Jul-Aug;14(4): 233-7.

20. Olympio KP, Bardal PA, Cardoso VE, Oliveira RC, Bastos JR, Buzalaf MA. Low-fluoride dentifrices with reduced $\mathrm{pH}$ : fluoride concentration in whole saliva and bioavailability. Caries Res. 2007 Sep-Oct;41(5):365-70.

21. Marinho VC, Higgins JP, Sheiham A, Logan S. Combinations of topical fluoride (toothpastes, mouthrinses, gels, varnishes) versus single topical fluoride for preventing dental caries in children and adolescents. Cochrane Database Syst Rev. 2004;(1):CD002781. 